\title{
El arbitraje comercial internacional en América Latina
}

\author{
Diego Ricardo Galán Barrera
}

\begin{abstract}
For more than a century in Latin America, several international treaties have been issued to regulate international commercial arbitration. This essay presents a historical review of the conventions where these treaties have been produced, and also examines their current validity and enforcement in relation to the unification process of private international law.
\end{abstract}

\section{Introducción}

La trascendencia del arbitraje comercial internacional en la solución de conflictos del mundo moderno tiene un reflejo singular en América Latina, toda vez que su implantación, aplicación y reconocimiento han sido materias objeto de regulación desde mucho antes de que esfuerzos similares se emprendieran en Europa o en los Estados Unidos. Esto amerita, por lo tanto, desde la óptica del derecho comparado, que se efectúe una revisión ordenada y sistemática de su complexión regulatoria, como un punto de partida de estudios ulteriores que se llegaren a producir acerca de su eficacia respecto de los negocios internacionales que se llevan a cabo en el hemisferio, así como de la conveniencia de seguir resguardando la reglamentación con un criterio eminentemente regional. En tal virtud, este ensayo tiene como propósito central realizar un relato del recorrido histórico del arbitraje comercial internacional en el contexto latinoamericano, particularmente a través de la reseña pormenorizada de las convenciones internacionales que lo han tratado y regulado. El objetivo es que el lector que se aproxime a su contenido encuentre en él una fuente de información clara, basada en una configuración definida, que le sirva de estructura funcional para acometer ejercicios analíticos sobre aspectos puntuales de la temática arbitral internacional. Para lograr el objetivo propuesto, he procedido a seleccionar y revisar no sólo los instrumentos internacionales celebrados a lo largo de más de un siglo en el entorno latinoamericano en materia de arbitraje comercial 
internacional, sino también la bibliografía que sobre el particular es posible encontrar en diversas bibliotecas universitarias de Colombia, lo mismo que la consulta a las inconmensurables bases de datos y la necesaria búsqueda en diferentes páginas de la internet, ese increíble sistema de acopio de información cada vez más amplio, generoso, abundante y diverso.

Ahora bien, todo ese repertorio normativo, elaborado durante décadas por juristas latinoamericanos de distintas generaciones, plantea en los tiempos actuales un dilema cuya solución deberá ser producto tanto de las necesarísimas discusiones académicas que deben fomentarse, como de las decisiones políticas que deben comenzar a ambientarse, en el sentido de definir cuáles de ellas tienen vigencia y cuáles no, así como confrontarlas con esquemas normativos de similar estirpe, pero de mayor influjo, lo cual supone realizar escrutinios comparativos en el núcleo mismo del concepto de unificación del derecho internacional privado.

Esbozada así tal disyuntiva, y mientras no se concrete una estrategia encaminada a dilucidar el problema en un ámbito más universal, acorde con los retos de la globalización jurídica, cabe anticipar que, para efectos de dotar de certidumbre a los operadores jurídicos, debe ser la Organización de Estados Americanos el foro privativo que determine acerca de la validez material de algunos de los tratados que se examinarán a continuación, pudiendo expedir, tal vez, un texto refundido que ordene los contenidos y concentre la aplicación eficaz de la normatividad en tratándose del arbitraje comercial internacional o, como mínimo, que expida una declaración que indique, sin lugar a dudas, que son las convenciones de Panamá (1975) y Montevideo (1979) el conjunto normativo que con mayor idoneidad regula la temática del arbitraje comercial internacional.

\section{Aproximación al tema y breve recuento de su historia}

El arbitraje, tan antiguo ${ }^{1}$ como las divergencias entre humanos, cada día se afianza como una institución jurídica de singular naturaleza, que alcanza una trascendencia adicional en la medida en que los intereses involucrados corresponden a los del comercio internacional. En tal virtud, ha sido del arbitraje comercial internacional de donde se ha desprendido toda una novísima

${ }^{1}$ Cfr. Antiguo Testamento, Libro del Génesis 31(38); Platón, De Legibus, Libros 6 y 12; Ley de las XII Tablas, tabula XII: “(...) Si servo furtum faxit noxiamve noxit. Si vindiciam falsam tulit, si velit is...tor arbitros tris dato, eorum arbitrio..fructus duplione damnum decidito (...)"; Ley Licinia, Digesto $(4,8,17,18,6)$. Cfr. González de Cancino, Emilssen, "Arbitraje romano”, en: Silva Romero y Mantilla Espinosa (coords.), El Contrato de Arbitraje, Facultad de Jurisprudencia. Universidad del Rosario, Legis, Bogotá, 2005, pp. 21-39. 
forma de enfocar el derecho de los negocios, no sólo por el remozamiento impreso a la noción de lex mercatoria, ${ }^{2}$ sino también por la reivindicación de la costumbre y los usos comerciales internacionales como fuente jurídica, por la creación de entidades especializadas que han desarrollado el concepto de arbitraje institucional o administrado, ${ }^{3}$ hasta el punto que la jurisprudencia de ellos emanada tiene un influjo uniformizador en la aplicación del derecho en las más diversas latitudes y, finalmente, por la necesidad de los operadores del comercio internacional, de los organismos multilaterales y de los gobiernos nacionales de optar por la utilización de métodos de solución de controversias alternativos a la justicia estatal.

Por contera, no debe sorprender, entonces, que desde mediados del siglo antepasado las naciones americanas hayan adelantado acercamientos y diseñado proyectos de regulación del arbitraje internacional en asuntos privados. La confluencia de los distintos pensamientos, bajo la égida de una pléyade irrepetible de juristas americanos, vinculados por propósitos comunes, cuando la interacción de los actores internacionales y su propio entorno era aún incipiente, debe encontrar hoy una sólida vocación de continuidad, no sólo en su estudio sino en su cabal aplicación por parte de las nuevas generaciones de abogados, especialmente cuando la globalización económica y los procesos de cooperación e integración en materia comercial configuran la nueva realidad de las relaciones internacionales de nuestros pueblos.

En este orden de ideas, se debe destacar que la regulación jurídica del arbitraje comercial internacional tiene como centro de gravedad la necesidad que encuentra un laudo arbitral dictado en un determinado lugar de ser reconocido en el territorio donde puede ser ejecutado. Es apenas obvio que cuando el fallo

${ }^{2}$ Cfr. Baron, Gesa. "Do the UNIDROIT Principles of International Commercial Contracts form a new lex mercatoria?" Disponible en Internet: < http://www.cisg.law.pace.edu/cisg/biblio/baron. html>; Gabor, Francis A., "Stepchild of the New Lex Mercatoria: Private International Law from the United States Perspective”, Disponible en internet: < http:/cisgw3.law.pace.edu/cisg/ biblio/gabor.html > ; Alvarez Londoño S.J., Luis Fernando y Diego Ricardo Galán Barrera, Derecho Internacional Privado, Parte General, Pontificia Universidad Javeriana, Facultad de Ciencias Jurídicas - CEDI, Bogotá, 2002, pp. 97-99; Calvo Caravaca, Alfonso-Luis y Javier Carrascosa González, Derecho Internacional Privado, Vol 1., 6 ed., Granada, Comares, 2005, p. 102; Jaramillo Vargas, Jorge, "La lex mercatoria: mito o realidad", en: Negocios Internacionales - tendencias, contratos e instrumentos (octubre 20, 21, 22 de 1998). Tercer Congreso Iberoamericano de Derecho Empresarial, Cámara de Comercio de Bogotá, pp. 35-52; Espinosa Pérez, Carlos Antonio, "La lex mercatoria: el verdadero derecho de los negocios internacionales", en: Revista de Derecho Privado, V. III, noviembre de 1993, Facultad de Derecho, U. de los Andes, Bogotá, pp. 6-30; Mantilla Serrano, Fernando, "Ius Mercatorum fuente del derecho internacional", en: El Arbitraje en los conflictos económicos internacionales, XIII Conferencia Interamericana de Arbitraje Comercial, agosto de 1995, pp. 62-73.

${ }^{3}$ Es el caso ad. ex. de la Cámara de Comercio Internacional a través de su Corte Internacional 
arbitral es honrado por las partes de manera voluntaria y sin apremios, que es lo que normalmente acontece, no exige ningún tipo de injerencia normativa complementaria para alcanzar su efectividad. Pero cuando, excepcionalmente, se requiere del procedimiento de exequátur, como aval indispensable para enervar la idoneidad del fallo y las condiciones en que fue proferido, surgen, entonces, las convenciones internacionales como habilitadoras de tal función garantista.

Todo este conjunto de circunstancias ha constituido la rationae materia de la regulación jurídica del arbitraje comercial internacional en Latinoamérica, cuyo breve recuento abordo a continuación, siendo todavía una asignatura pendiente la determinación de cuál es la vigencia real y material de toda la normatividad que examinaré en la siguiente sección, resaltando, con todo, la sentida necesidad de comenzar a perfilar estudios consistentes de derecho comparado sobre el particular.

Indiscutiblemente, cualquier sondeo relacionado sobre un tema jurídico común a los latinoamericanos encuentra su punto de partida en el célebre Congreso de Panamá, ${ }^{4}$ convocado por el Libertador y el cual se reunió del 22 de junio al 15 de julio de $1826,{ }^{5}$ toda vez que allí se encuentra la génesis político-jurídica de la actual Organización de los Estados Americanos (OEA), gestora de algunos de los instrumentos internacionales que regulan el arbitraje comercial internacional en nuestras latitudes. De igual manera, las denominadas Conferencias para la Codificación del Derecho Internacional Privado, reunidas en Lima promediando el siglo XIX ${ }^{6}$ si bien no produjeron resultados regulatorios concretos, no obstante constituyen un valioso acervo histórico que no se puede soslayar al momento de auscultar el contenido de la normatividad que sobrevino.

Posteriormente, en 1877, de nuevo en la capital peruana, se instaló un congreso de jurisconsultos, conocido como el Congreso de Lima, ${ }^{7}$ el cual elaboró un tratado de 60 artículos que, entre otras materias, reguló ciertos

\footnotetext{
de Arbitraje.

${ }^{4}$ Cfr. Dotación Carnegie para la Paz Internacional, Conferencias Internacionales Americanas. 1889-1936. Washington: Publicaciones de la Dotación Carnegie para la Paz Internacional, 1938, p. ix.

${ }^{5}$ Ibídem, p. xxiii. Asimismo, Cfr. Alvarez Londoño y Galán Barrera, Op. Cit, p. 104.

${ }^{6}$ Las conferencias se verificaron en 1847,1861 y 1867.

${ }^{7}$ Cfr. Monroy Cabra, Marco Gerardo. Tratado de Derecho Internacional Privado. 5 ed. Santa Fe de Bogotá, Temis, 1998 p. 42; Garro, Alejandro, Armonización y unificación del derecho privado en América Latina: esfuerzos, tendencias y realidades. Saggi, Conference e Seminari 5. Centro di studi e ricerche di diritto comparato e straniero (directo da M. J. Bonell), p. 9; Cfr. Lagos, Enrique, "Memoria del Seminario sobre Aplicación de Normas Internacionales", Granada, Nicaragua, (septiembre de 1996), p. 1-8. Disponible en internet: < http://www.oas.org/legal/spanish/osaj/ seminario_nicaragua_1996.doc.
}

\section{PRECEDENTE}


DIEGO RICARDO GALÁN BARRERA

EL ARBITRAJE COMERCIAL INTERNACIONAL

EN AMÉRICA LATINA

aspectos relativos a la ejecución de sentencias extranjeras y la legalización. No obstante, debe resaltarse este congreso por la elevada calidad del material de referencia utilizado. ${ }^{8}$

\section{La regulación convencional del arbitraje comercial internacional en América Latina}

Acto seguido, se examinarán algunos de los tratados y conferencias internacionales que han versado sobre el arbitraje comercial internacional en nuestra latitud.

\subsection{Tratado de derecho procesal internacional, firmado en Montevideo el 11 de enero de 1889}

Este convenio fue el primero de los ocho tratados y el protocolo adicional que se firmaron con ocasión del Primer Congreso Sudamericano de Derecho Internacional Privado, celebrado en la capital uruguaya entre el 25 de agosto de 1888 y el 18 de febrero de 1889. Consta de 3 títulos y 16 artículos. El título I está compuesto por los dos primeros artículos y se refiere a las disposiciones generales. El título II, contentivo de los artículos 3 y 4, hace relación a las legalizaciones. El título III, intitulado "Del cumplimiento de los exhortos, sentencias y fallos arbitrales", contiene ocho artículos. Los artículos 5 a 7 se refieren a las sentencias y a los fallos arbitrales. El artículo 8 versa sobre los actos de jurisdicción voluntaria y del artículo 9 al 12 se dispone acerca de los exhortos y cartas rogatorias. Finalmente, en los artículos 13 a 16 se prevén las disposiciones generales correspondientes.

El tratado fue suscrito el 11 de enero de 1889 por la República Argentina, por la República de Bolivia, por el Imperio de Brasil (que no lo ratificó), por la República de Chile, por la República del Paraguay, por la República del Perú y por la República Oriental del Uruguay. Posteriormente, depositaron los respectivos instrumentos de ratificación la República Argentina, la República de Bolivia, la República del Paraguay, la República del Perú y la República Oriental del Uruguay. ${ }^{9}$ Colombia adhirió mediante la ley 68 del 11 de noviembre de 1920.

\footnotetext{
${ }^{8}$ Cfr. Monroy Cabra, Op. Cit., p. 42. El autor, siguiendo la obra del jurista brasileño Haroldo Valladáo, Direito internacional privado, afirma que en el Congreso de Lima se utilizaron “ (...) en sus trabajos los textos de los códigos americanos y las obras de Story, Bello y Freitas, así como las ideas de Mancini, Fiore, Mazonni, Brocher, Laurent y Pradier Fóder (...)”.

${ }^{9}$ Cfr. Mac Lean U., Roberto. Derecho del Comercio Internacional (Nuevas Tendencias), Bogotá, Temis, 1982, p. 26.
} 
En relación con el arbitraje comercial, el artículo 5o señala que “(...) los fallos arbitrales dictados en asuntos civiles y comerciales en uno de los Estados signatarios, tendrán en los territorios de los demás, la misma fuerza que en el país en que se han pronunciado, si reúnen los requisitos siguientes ${ }^{10}(\ldots)$ ”. De la misma manera, en el artículo $6^{\mathrm{O}}$ se enuncian los "(...) documentos indispensables ${ }^{11}$ para solicitar el cumplimiento de (...) (los) (...) fallos arbitrales". Finalmente, el artículo 7o establece que “(...) el carácter ejecutivo (...) de (los) (...) fallos arbitrales, y el juicio a que su cumplimiento dé lugar, serán los que determine la ley de procedimiento del Estado en donde se pida la ejecución (...)".

En tal virtud, los Estados que han manifestado su consentimiento en obligarse por dicho tratado han aceptado la reciprocidad diplomática para la ejecución de los laudos arbitrales que se dictaren en sus respectivos territorios, admitiendo los requisitos documentales para el correspondiente exequátur y la sujeción del trámite a las leyes procesales del foro del país ejecutor.

\subsection{Primera Conferencia Internacional Americana, celebrada en Was- hington del 2 de octubre de 1889 al 19 de abril de 1890}

En los dictámenes, recomendaciones y resoluciones adoptados por la Primera Conferencia Internacional Americana (Primera Conferencia Panamericana), ${ }^{12}$ celebrada en Washington del 2 de octubre de 1889 al 19 de abril de 1890, se resolvió “(...) Que se recomiende á los Gobiernos representados en esta Conferencia, que no hayan aceptado todavía los tratados de derecho internacional privado, civil, comercial y procesal del Congreso de Montevideo reunido el 25 de Agosto de 1888, hagan examinar y estudiar dichos tratados á fin de que, dentro del término de un año, contado desde la fecha de clausura de esta Conferencia, expresen si adhieren á ellos (...)". ${ }^{13}$

Frente al carácter perentorio del término contemplado en la recomendación reseñada, no sobra comentar lo curioso de la dilación de la adhesión final de

10 Son cuatro los requisitos exigidos: Que el fallo arbitral haya sido proferido por un tribunal competente en la esfera internacional; que el fallo tenga el carácter de ejecutoriado o con fuerza de cosa juzgada en el Estado donde hubiere sido expedido; que la parte afectada con el fallo hubiere sido legalmente citada y representada conforme a la ley del país donde se dictó el fallo y que el fallo no se oponga a las leyes de orden público del país donde debe ejecutarse.

${ }^{11}$ Los cuales son tres, así: la copia íntegra del fallo arbitral; la copia de las piezas necesarias para acreditar la debida citación a las partes y la copia auténtica del auto en que se declare que el laudo tiene el carácter de ejecutoriado.

${ }^{12}$ Esta Conferencia estableció la Unión Internacional de las Repúblicas Americanas, precursora cercana de la Organización de Estados Americanos, así como su Secretaría Permanente, la Oficina Comercial de las Repúblicas Americanas. Disponible en Internet: < http://www.oas.org/key_issues/ spa/KeyIssue_Detail.asp?kis_sec $=17>$ S

${ }^{13}$ Cfr. Dotación Carnegie para la Paz Internacional, Op. Cit., p. 14. 
DIEGO RICARDO GALÁN BARRERA

EL ARBITRAJE COMERCIAL INTERNACIONAL

EN AMÉRICA LATINA

Colombia a los tratados de derecho civil y comercial internacional de 1889 , pues en lugar de haberse hecho en el período sugerido por la conferencia diplomática, tal acto vino a demorarse en la práctica la friolera de 103 años. ${ }^{14}$

\subsection{Quinta Conferencia Internacional Americana, celebrada en Santiago del 25 de marzo al 3 de mayo de 1923}

En las resoluciones, acuerdos y mociones adoptados por la Quinta Conferencia Internacional Americana, celebrada en Santiago del 25 de marzo al 3 de mayo de 1923, se resolvió “(...) Recomendar que se organicen Cámaras de Comercio, en los centros de comercio del Continente americano (...) y que estas Cámaras de Comercio celebren entre sí convenios para el arbitraje extrajudicial de las controversias mercantiles (...)" e igualmente, recomendar a la Alta Comisión Inter-Americana “(...) el estudio del principio del arbitraje obligatorio como medio de resolver las diferencias que se susciten entre comerciantes domiciliados en diferentes países $(. .). "{ }^{15}$

A pesar del carácter no vinculante de este tipo de instrumento, de todas maneras cabe mencionar que la recomendación no aplicaba, pues para la fecha de la conferencia internacional ya la Cámara de Comercio de Bogotá tenía algo más de tres décadas de fundada, ${ }^{16}$ la de Medellín tenía casi 20 años, ${ }^{17}$ la de Cali iba a cumplir 13 años ${ }^{18}$ y la de Barranquilla 7 años. ${ }^{19}$

\subsection{Sexta Conferencia Internacional Americana, celebrada en La Habana del 16 de enero al 20 de febrero de 1928 - Convención sobre derecho internacional privado, suscrita en La Habana el 20 de febrero de 1928 (Código de derecho internacional privado o 'Código Bustamante')}

De las varias convenciones suscritas en la Sexta Conferencia Internacional Americana, celebrada en La Habana del 16 de enero al 20 de febrero de

${ }^{14}$ Colombia se adhirió mediante la ley 40 de 1933. Sin embargo, dicha ley fue muy posteriormente declarada inconstitucional por la Corte Suprema de Justicia, el 18 de junio de 1987, razón por la cual hubo necesidad de expedir la ley 33 del 30 de diciembre de 1992, aprobatoria del señalado Tratado de Derecho Comercial Internacional, conjuntamente con el Tratado de Derecho Civil Internacional. Merced al control previo de constitucionalidad, en un fallo muy polémico, la Corte Constitucional, mediante sentencia C-276 del 22 de julio de 1993 (expediente L.A.T. 013) los declaró exequibles junto con la ley aprobatoria.

Disponible en Internet: < http://www.secretariasenado.gov.co/leyes/L0033_92.HTM>

${ }^{15}$ Cfr. Dotación Carnegie para la Paz Internacional, Op. Cit., p. 250.

16 Disponible en Internet: <http://camara.ccb.org.co/contenido/contenido. aspx? catID $=98 \&$ conID $=335>$

${ }^{17}$ Disponible en Internet: <http://www.camaramed.org.co/corporativohistoria.asp >

${ }^{18}$ Disponible en Internet: <http://www.ccc.org.co/hist.html>

19 Disponible en Internet: < http://www.camarabaq.org.co/cms/content.jsp?id=com.tms.cms. 
1928, la más significativa fue aquella que aceptaba y ponía en vigor el Código de Derecho Internacional Privado, a ella anexo, más conocido como 'Código Bustamante', ${ }^{20}$ en honor del insigne jurista cubano don Antonio Sánchez de Bustamante y Sirven, quien ofició como Presidente de la Conferencia. El Código de Derecho Internacional Privado consta de 437 artículos divididos en un título preliminar y cuatro libros, el último de los cuales versa sobre Derecho Procesal Internacional.

En efecto, el capítulo I (Materia civil) del título décimo (Ejecución de sentencias dictadas por tribunales extranjeros) de dicho libro 4으, regula la materia, particularmente por la remisión hecha por el artículo 432 en cuanto que "(...) El procedimiento y los efectos regulados en los artículos anteriores (arts. 423 a 431) se aplicarán en los Estados contratantes a las sentencias dictadas en cualquiera de ellos por árbitros (...), siempre que el asunto que los motiva pueda ser objeto de compromiso conforme a la legislación del país en que la ejecución se solicite (...)".

El artículo 423 establece los seis requisitos ${ }^{21}$ para que una sentencia dictada en un Estado contratante tenga fuerza y pueda ejecutarse en los demás Estados contratantes. Los artículos 424 a 426 se refieren a determinados requisitos de procedibilidad ${ }^{22}$ del fallo dictado. Los artículos 427 y 428 prevén lo relativo a la forma de comparecer ${ }^{23}$ del citado cuando su domicilio está en el extranjero. Los artículos 429 a 431 hacen relación al cumplimiento o no del fallo proferido en el extranjero. ${ }^{24}$ Finalmente, el artículo 433 dispone que ese mismo procedimiento se aplicará "(...) a las sentencias civiles dictadas en cualquiera de los Estados contratantes por un tribunal internacional, que se refieran a personas e intereses privados (...)".

102 article. Article_80e2ead7-c86a89b3-1c9d17e0-f6055488>

${ }^{20}$ Ver el listado de países que lo ratificaron y las notas de vigencia y fechas de entrada en vigor. Disponible en Internet: < http://www.oas.org/juridico/spanish/firmas/a-31.html>

${ }^{21}$ Es decir, que el tribunal que profiera el fallo tenga competencia, citación personal a las partes, que el fallo no contravenga el orden público del país de ejecución, que en el Estado donde se dicte el fallo sea ejecutorio, que sea traducido oficialmente y que el documento que lo contenga sea auténtico.

${ }^{22}$ Los requisitos de procedibilidad hacen referencia a que la ejecución se solicite al tribunal competente, a que respecto de ella se concedan los recursos procedentes y a que dicho tribunal oiga previamente a la parte contra quien se dirija y al ministerio público.

${ }^{23}$ La citación se hará por exhorto o comisión rogatoria y si la parte no compareciere luego de transcurrido el término el asunto continuará su marcha.

${ }^{24} \mathrm{Si}$ el fallo se deniega, se devuelve al que la hubiese presentado. Si el fallo se cumple, la ejecución se debe ajustar a las normas internas para las ejecuciones de sus propios fallos. Si el fallo no fuere susceptible de ser ejecutado, producirá en los demás Estados el efecto de cosa juzgada, si reúne los requisitos correspondientes. 
DIEGO RICARDO GALÁN BARRERA

EL ARBITRAJE COMERCIAL INTERNACIONAL

EN AMÉRICA LATINA

Colombia lo suscribió consignando una declaración de reserva y todavía no lo ha ratificado; por lo tanto, dicho instrumento no rige las relaciones de Colombia con los demás ratificantes o adherentes. Empero, cabe destacar que el Código de derecho internacional privado es tal vez el más grande y complejo esfuerzo de codificación internacional realizado en el mundo, lo cual exalta sus virtudes y pondera sus aciertos, no siendo improbable que su alcance pueda remozarse, dando así cabal cumplimiento a la voluntad de sus creadores.

De igual manera, en el acta final de la conferencia ${ }^{25}$ y en el mismo sentido de la resolución correspondiente ${ }^{26}$ en la Quinta Conferencia Internacional Americana, la asamblea decidió:

[...] Recomendar que se organicen Cámaras de Comercio, en los centros comerciales del continente americano en donde exista un movimiento de exportación e importación cuya importancia justifique el establecimiento de tales asociaciones y que estas Cámaras de Comercio celebren entre sí convenios para el arbitraje extrajudicial de las controversias mercantiles [...] y también recomendó a la Alta Comisión Inter-Americana [...] el estudio del principio del arbitraje obligatorio como medio de resolver las diferencias que se susciten entre comerciantes domiciliados en diferentes países [...].

\subsection{Séptima Conferencia Internacional Americana, celebrada en Monte- video del 3 al 26 de diciembre de 1933}

El 23 de diciembre de 1933 la Séptima Conferencia Internacional Americana aprobó su cuadragésima primera resolución, por medio de la cual resolvió [...] Recomendar a las respectivas Cámaras de Comercio la adopción de una convención tal como la realizada sobre arbitraje internacional y que ha sido concertada en el año 1916 entre la Bolsa de Comercio de Buenos Aires y la Cámara de Comercio de Estados Unidos de Norte América [... $].{ }^{27}$ Asimismo, la resolución perfila unos:

\footnotetext{
${ }^{25}$ Disponible en Internet: < http://biblio2.colmex.mx/coinam/coinam_1889_1936/base2.htm>

${ }^{26}$ Supra. 4.3.

${ }^{27}$ Cfr. Dotación Carnegie, Op. Cit., pp. 522-523. Asimismo, cfr. Pérez García, Arturo Rafael.

"Una nueva forma de valorar el tratado de libre comercio de América del Norte, a partir de las controversias suscitadas de acuerdo con el capítulo once", en: Revista del Centro de Investigación Universidad La Salle (ene-jun), V. 5. No. 20. México, 2003, pp. 107-111.

Disponible en Internet: <http://redalyc.uaemex.mx/redalyc/pdf/342/34252009.pdf>

Cfr. Montoya, Ulises, "La Comisión Interamericana de Arbitraje Comercial", en: Revista Iberoamericana de Arbitraje y Mediación, particularmente en la nota de pie No 2 al citar el artículo de Charles Robert Norberg, "Reciente Evolución en el Arbitraje Comercial Interamericano", publicado en: Case Western Reserve Journal of International Law; V. 13. No. 1, invierno de 1981.

Disponible en Internet: <http://www.servilex.com.pe/arbitraje/colaboraciones/historiaciac.
} 
“(...) lineamientos de normas de procedimiento o práctica que se consideran esenciales en las reglas y reglamentos de las asociaciones comerciales, para que funcione con éxito un sistema interamericano de arbitraje:

(...) El compromiso de acudir al arbitraje, ya sea para controversias existentes o futuras, debe ser válido y obligatorio; y en los casos en que no pueda exigirse su cumplimiento por la ley, deberán establecerse medidas disciplinarias de índole comercial.

Las partes deben tener la facultad de designar árbitros, de llenar las vacantes que ocurran o de establecer un procedimiento para llenarlas.

El procedimiento a que se sujeten los árbitros de facto debe ser definido con toda precisión por las partes o por la asociación bajo cuyos auspicios va a celebrarse el arbitraje

La imparcialidad absoluta del árbitro y el derecho de recusación o remoción, deben ser asegurados por la asociación bajo cuyos auspicios se celebre el arbitraje en la forma prescripta (sic) por las reglas o reglamentos que rijan el procedimiento.

Las reglas deben estipular un número impar de árbitros y todos ellos deben participar en el arbitraje desde su iniciación.

Los laudos, en todos los casos, deben ser unánimes o por mayoría de votos.

Las reglas deben estipular la renuncia del derecho de apelación; renuncia que debe ser obligatoria para las partes y que limitará las causas de apelación a cuestiones de procedimiento o a aquellas cuestiones de derecho que ambas partes acuerden someter a los tribunales.

En los casos en que la ley sea inadecuada para obligar el cumplimiento del laudo, debe ampliarse el uso de medidas disciplinarias por la asociación cuyos miembros participen en el arbitraje y rehúsen cumplir con los términos del laudo $(\ldots) "{ }^{28}$

194 Finalmente, la resolución prevé que para estrechar las relaciones entre las asociaciones comerciales americanas y con independencia del control oficial “(...) Se constituya una Agencia Comercial Interamericana (la futura CIAC), ${ }^{29}$ que represente los intereses de todas las Repúblicas y que asuma la responsabilidad de implantar un sistema interamericano de arbitraje, como una de sus funciones primordiales (...)”. ${ }^{30}$

html > El texto de la resolución se puede consultar en <http://biblio2.colmex.mx/coinam/ coinam_1889_1936/base2.htm>

${ }^{28}$ Ibídem, p. 523. Igualmente, Cfr. Monroy Cabra, Marco Gerardo, Arbitraje Comercial Nacional e Internacional, 2 ed. Santafé de Bogotá, Legis, 1998, p. 137.

${ }^{29}$ Infra. 4.6.

${ }^{30}$ Cfr. Dotación Carnegie, Op. Cit., p. 523. Cfr. asimismo: < http://biblio2.colmex.mx/coinam/ coinam_1889_1936/base2.htm> 
DIEGO RICARDO GALÁN BARRERA

EL ARBITRAJE COMERCIAL INTERNACIONAL

EN AMÉRICA LATINA

\subsection{Comisión Interamericana de Arbitraje Comercial (CIAC), organizada el 25 de abril de 1934}

El Consejo Directivo de la Unión Panamericana, con base en la resolución aprobada el 23 de diciembre de 1933 por la Séptima Conferencia Internacional Americana, organizó, escasos cuatro meses después, la Comisión Interamericana de Arbitraje Comercial (CIAC). ${ }^{31}$ Entre sus objetivos está el "(...) establecer (y) mantener un sistema de métodos alternativos de resolución de disputas de carácter comercial mediante la utilización del arbitraje y la conciliación (...) fomentar el conocimiento y difusión del sistema y promover la adecuada interpretación y aplicación de la Convención de Panamá (...)”. ${ }^{32}$ Está integrada por un delegado y su suplente por cada una de las veinte secciones nacionales en ella representadas, que se reúnen por lo menos una vez cada dos años. Su estructura organizacional se compone de un consejo, el comité ejecutivo, la presidencia, 3 vicepresidencias y un director general. Tiene un reglamento de procedimientos que entró en vigor el 10 de abril de 2002. Actualmente, las reglas contienen 4 secciones y 39 artículos y un procedimiento que consta de seis apartados muy puntuales. ${ }^{33}$

Es interesante advertir que a la Comisión pertenecen los países miembros a través de secciones nacionales y de secciones asociadas. En el caso colombiano, la representatividad de la primera la tiene el Centro de Conciliación y Arbitraje de la Cámara de Comercio de Bogotá, en donde, valga señalarlo, hoy está domiciliada la CIAC, ${ }^{34}$ y respecto de la segunda es el Centro de Conciliación, Arbitraje y Amigable Composición de la Cámara de Comercio de Medellín la entidad registrada bajo esa calidad. ${ }^{35}$

\subsection{Tratado de derecho procesal internacional, firmado en Montevideo el 19 de marzo de 1940}

Con motivo de la conmemoración de los cincuenta años del Primer Congreso Sudamericano de Derecho Internacional Privado, los gobiernos de Uruguay y Argentina convocaron al Segundo Congreso Sudamericano

\footnotetext{
${ }^{31}$ Disponible en Internet: <http://www.ciac-iacac.org/default.asp >

32 Infra. 4.10. Disponible en Internet: <http://www.ciaciacac.org/paginas.asp?pub_id $=5 \&$ \&at $\mathrm{id}=2 \&$ cat_tit $=$ Acerca $\% 20 \mathrm{de} \% 20 \mathrm{la} \% 20 \mathrm{CIAC}>$

${ }^{33}$ Cfr. Monroy Cabra, Arbitraje comercial nacional e internacional, 2 ed. Santafé de Bogotá: Legis, 1998, p. 138.

${ }^{34}$ Cfr. Montoya, Op. cit. Disponible en Internet: < http://www.servilex.com.pe/arbitraje/ colaboraciones/historiaciac.html>

${ }^{35}$ Cfr. CIAC. Disponible en Internet: < http://www.ciac-iacac.org/paginas.asp?pub_id $=8 \&$ \&at_ $\mathrm{id}=2 \&$ cat_tit $=$ Acerca $\% 20 \mathrm{de} \% 20 \mathrm{la} \% 20 \mathrm{CIAC}>$
} 
de Derecho Internacional Privado, el cual se celebró en dos fases: la primera que se reunió en el segundo semestre de 1939 y la segunda fase que se reunió durante el primer semestre de 1940.

En total se firmaron cinco tratados y un protocolo adicional. Uno de ellos fue el Tratado de derecho procesal internacional, el cual consta de 4 títulos y 29 artículos. El título I, está compuesto por los dos primeros artículos y se refiere a las disposiciones generales. El título II, contentivo de los artículos 3 y 4 hace relación a las legalizaciones. El título III, intitulado "Del cumplimiento de los exhortos, sentencias y fallos arbitrales", contiene once artículos. Los artículos 5 a 9 se refieren a las sentencias y los fallos arbitrales. El artículo $10^{\circ}$ versa sobre los actos procesales no contenciosos y del artículo 11 a 15 se dispone acerca de los exhortos y cartas rogatorias. El título IV que comprende los artículos 16 a 25 versa sobre el concurso civil de acreedores. Finalmente, en los artículos 26 a 29 se contemplan las disposiciones generales correspondientes.

El tratado fue suscrito el 19 de marzo de 1940 por la República Argentina, por la República de Bolivia, por la República de Colombia, por los Estados Unidos del Brasil, por la República del Paraguay, por la República del Perú y por la República Oriental del Uruguay. Posteriormente, depositaron los respectivos instrumentos de ratificación la República Argentina, la República del Paraguay y la República Oriental del Uruguay. Colombia no lo ha ratificado y, por ende, no está en vigor en este país.

En relación con el arbitraje comercial, el artículo 5ํㅗㄹ señala que “...los fallos arbitrales dictados en asuntos civiles y comerciales en uno de los Estados signatarios, tendrán en los territorios de los demás, la misma fuerza que en el país en donde fueron pronunciados, si reúnen los requisitos siguientes: (...)" ${ }^{36}$ De la misma manera, en el artículo 6o se enuncian los "...documentos indispensables para solicitar el cumplimiento de...(los)...fallos arbitrales...". 37

Igualmente, el artículo 7ํㅡㄹ establece que:

[...] la ejecución [...] de los fallos arbitrales [...] deberá pedirse a los jueces o tribunales competentes, los cuales, con audiencia del Ministerio Público [...] ordenarán su cumplimiento por la vía que corresponda, de acuerdo con lo que a ese respecto disponga la ley de procedimiento local [...].

\footnotetext{
${ }^{36}$ Son cuatro los requisitos exigidos: Que el fallo arbitral haya sido dictado por un tribunal competente en la esfera internacional, que el fallo tenga el carácter de ejecutoriado o con fuerza de cosa juzgada en el Estado donde hubiere sido pronunciado, que la parte afectada con el fallo hubiere sido legalmente citada y representada conforme a la ley del país donde se dictó el fallo y que el fallo no se oponga a las leyes de orden público del país donde debe cumplirse

${ }^{37}$ Los cuales son tres, así: la copia íntegra del fallo arbitral, la copia de las piezas necesarias para acreditar la debida citación a las partes y la copia auténtica del auto en que se declare que el laudo tiene el carácter de ejecutoriado.
}

\section{PRECEDENTE}


Acto seguido, el artículo 8 reza:

[...] El juez a quien se solicite el cumplimiento de una sentencia extranjera, podrá, sin más trámite y a petición de parte y aún de oficio, tomar todas las medidas necesarias para asegurar la efectividad de aquel fallo, conforme a lo dispuesto por la ley del Tribunal local, sobre secuestros, inhibiciones, embargos $\mathrm{u}$ otras medidas preventivas $[\ldots]$

Finalmente, el artículo 9 dispone:

[...] Cuando sólo se trate de hacer valer como prueba la autoridad de cosa juzgada [...] de un fallo, deberá ser presentado en juicio, con la documentación a que se refiere el artículo 6을 en el momento que corresponda según la ley local; y los jueces o tribunales se pronunciarán sobre su mérito en la sentencia que dicten, previa comprobación, con audiencia del Ministerio Público, de que se ha dado cumplimiento a lo dispuesto en el artículo 5으 [...].

Este tratado de Montevideo de 1940 se asemeja a su homólogo de 1889 en relación con el contenido de los artículos 5 y 6, referente a los requisitos del laudo y los documentos necesarios para hacerlo efectivo en el lugar de ejecución, los cuales, salvo pequeñísimas variaciones de redacción, son prácticamente idénticos, pero se diferencia en que en el tratado de 1940 se efectúa una vinculación del Ministerio Público en función garantista del derecho de defensa de la parte vencida y a la caracterización más activa de la gestión del juez de la ejecución del fallo, toda vez que se le dota de más poderes para permitir la efectividad del mismo.

\subsection{Convención de las Naciones Unidas sobre reconocimiento y ejecución de las sentencias arbitrales extranjeras, suscrita en Nueva York el 10 de junio de 1958}

La Convención sobre reconocimiento y ejecución de las sentencias arbitrales extranjeras, que tiene un alcance orbital y, por ende de gran impacto para los países latinoamericanos, surgió de un anteproyecto formulado por iniciativa de la Cámara de Comercio Internacional, el cual, a su turno, fue recogido por el Consejo Económico y Social de las Naciones Unidas habiendo redactado en 1955 un texto preliminar que fue sometido a consideración de los distintos Estados. ${ }^{38}$ Posteriormente, en la conferencia internacional celebrada en la sede

\footnotetext{
${ }^{38}$ Cfr. Monroy Cabra, Arbitraje comercial nacional e internacional, 2 ed. Santafé de Bogotá: Legis, 1998., p. 140.
} 
de las Naciones Unidas en la ciudad de Nueva York, del 20 de mayo al 10 de junio de 1958, se debatió el proyecto que desembocó en el texto suscrito por 24 Estados el último día de sesiones.

De conformidad con lo dispuesto por el numeral 1 de su artículo XII, dicha Convención entró en vigor "(...) el nonagésimo día siguiente a la fecha del depósito del tercer instrumento de ratificación o adhesión(...)”, vale decir, el 7 de junio de 1959. A la fecha son partes de la Convención de Nueva York más de 120 Estados, Colombia entre ellos, ${ }^{39}$ como adherentes.

La Convención sobre el reconocimiento y ejecución de las sentencias arbitrales extranjeras consta de 16 artículos. El numeral $1^{\circ}$ del artículo I contempla el ámbito de aplicación de la Convención, vale decir, el "(...) reconocimiento y la ejecución de las sentencias arbitrales dictadas en el territorio ${ }^{40}$ de un Estado distinto de aquel en que se pide el reconocimiento y la ejecución de dichas sentencias (...)”. Ahora bien, la misma disposición agrega que la 'sentencia arbitral' debe tener su "(...) origen en diferencias entre personas naturales o jurídicas (...)”. Y concluye el numeral 1o del artículo I, extendiendo el ámbito de aplicación a "(...) las sentencias arbitrales que no sean consideradas como sentencias nacionales en el Estado en el que se pide su reconocimiento y ejecución (...)".

El numeral 2으 del artículo I explica qué se entiende por "sentencia arbitral", comprendiendo en su significado tanto el arbitraje ad hoc como el arbitraje institucional o administrado. ${ }^{41}$ Finalmente, el numeral $3{ }^{\circ}$ del artículo I con-

\footnotetext{
${ }^{39}$ La adhesión de Colombia se verificó el 26 de septiembre de 1981. Debe anotarse que Colombia aprobó la Convención por medio de la Ley 39 de 1990. Sin embargo, resulta pertinente destacar que esta fue la segunda vez que el Congreso Nacional aprobó dicho instrumento. En efecto, la primera vez que se aprobó la Convención lo fue por medio de la Ley 37 de 8 de julio de 1979, 198 declarada inexequible por la Corte Suprema de Justicia (sentencia del 6 de octubre de 1988). Cfr. Monroy Cabra, Arbitraje comercial nacional e internacional, 2 ed. Santafé de Bogotá: Legis, 1998., pp. 140-146.

${ }^{40}$ Cfr. Chillón Medina, José María y José Fernando Merino Merchán, Tratado de arbitraje Privado Interno e Internacional. 2 ed. Madrid, Civitas, 1991, p. 501, donde se afirma que “(...) La nacionalidad de la sentencia se fija en relación a un criterio territorial (...)”. Igualmente, Cfr. Monroy Cabra, Arbitraje comercial nacional e internacional, 2 ed. Santafé de Bogotá: Legis, 1998, p. 141.

${ }^{41}$ Cfr. Eyzaguirre Echeverria, Rafael, "Ventajas del arbitraje. Eficacia y validez en el derecho iberoamericano", en: Alternativas a la justicia institucional. Arbitraje. Conciliación. Conferencias, Biblioteca de la Cámara de Comercio de Bogotá, Bogotá, 1986, p. 117. Cfr. Chillón Medina y Merino Merchán, Op. Cit., p. 501. Cfr. Monroy Cabra, Op. Cit. en nota al pie anterior, p. 140. Cfr. Morales Molina, Hernando, "El arbitraje nacional e internacional en Colombia", en: Alternativas a la justicia institucional. Arbitraje. Conciliación. Conferencias, Biblioteca de la Cámara de Comercio de Bogotá, Bogotá, 1986, p. 25. Asimismo, Cfr. Gamboa Morales, Nicolás, "La inmunidad soberana de jurisdicción en el marco del arbitraje comercial internacional. Evolución
} 
templa la posibilidad para un Estado contratante de hacer reservas ${ }^{42}$ “(...) En el momento de firmar o ratificar la presente convención, de adherirse a ella o de hacer la notificación de su extensión prevista en el artículo 10 (...)”. Tales reservas hacen relación a la facultad para ese Estado contratante de reconocer exclusivamente a su amparo las sentencias arbitrales procedentes de otros Estados contratantes, ${ }^{43}$ con base en un criterio de reciprocidad. ${ }^{44}$ Asimismo, las reservas pueden referirse a la aplicación de "(...) la convención a los litigios surgidos de relaciones jurídicas, sean o no contractuales, consideradas comerciales por su derecho interno (...)". 45

A su turno, el artículo II se refiere al convenio o pacto arbitral como un “acuerdo por escrito", destacando en su numeral $2^{\circ}$ que éste puede consistir en "(...) una cláusula compromisoria incluida en un contrato o un compromiso (...)", añadiendo, a continuación, que el acuerdo por escrito puede ser "(...) firmado por las partes o contenido en un canje de cartas y telegramas (...)”. Sobre este último particular, el Grupo de Trabajo sobre Arbitraje de la Comisión de las Naciones Unidas para el Derecho Mercantil Internacional (CNUDMI/ UNCITRAL), en su $36^{\circ}$ período de sesiones, efectuado en Nueva York del 4 al 8 de marzo de 2002, presentó un informe acerca de la labor realizada, en el cual se destaca el propósito de uniformizar el concepto de "acuerdo por escrito". ${ }^{46}$ En efecto, la debida concordancia entre el párrafo 2 o del artículo II de la Convención de Nueva York con el numeral $2^{\circ}$ del artículo $7^{\circ}$ de la ley modelo de la CNUDMI sobre arbitraje comercial internacional, también debía tener presente lo consignado en el párrafo 2o del artículo 7º de la Convención de las Naciones Unidas sobre Garantías Independientes y Cartas de Crédito Contingente y el párrafo $1^{\mathrm{O}}$ del artículo 6을 de la ley modelo de la CNUDMI sobre comercio electrónico, en cuanto a conceder validez a los acuerdos de arbitraje que se concertaran por medios electrónicos.

En el precitado grupo de trabajo se presentaron dos propuestas para poder hacer efectiva la armonización requerida. Una de ellas consistía en aprobar

y actualidad". Disponible en Internet: $<$ http://acj.org.co/index.phpcont $=$ actividad_academica/ posesion_gamboa_morales.htm>

${ }^{42}$ Argentina, Canadá, Ecuador, Estados Unidos, Guatemala, Trinidad Tobago y Venezuela, por vía de referencia, hicieron reservas. Ni Colombia ni Perú hicieron reservas. Tampoco Chile, España y México.

${ }^{43}$ Cfr. Fernández de la Gándara, Luis y Alfonso Luis Calvo Caravaca, Derecho Mercantil Internacional, 2 ed. Tecnos, Madrid, 1995, p. 775.

${ }^{44}$ Cfr. Monroy Cabra, Tratado de Derecho Internacional Privado, 5 ed. Santa Fe de Bogotá: Temis, 1998, p. 365. Cfr. Eyzaguirre, Op. Cit., pp. 116-117.

${ }^{45}$ Cfr. Holguín Holguín, Carlos, "El concepto de orden público en la Convención de Nueva York y otros comentarios", en: Alternativas a la Justicia Institucional. Arbitraje. Conciliación. Conferencias, Biblioteca de la Cámara de Comercio de Bogotá, Bogotá, 1986, p. 135. El ilustre internacionalista y ex-rector del Colegio Mayor de Nuestra Señora del Rosario, sostuvo que “(...) La Convención 
un instrumento interpretativo de lo que se quiere significar por "acuerdo por escrito", cuyo anteproyecto se elaboró en el 34 ํ período de sesiones. La otra propuesta radicaba en elaborar un protocolo de enmienda de la Convención de Nueva York. Dada la dificultad para obtener un consenso sobre el tema, la decisión por el momento se encuentra aplazada. ${ }^{47}$

El artículo III establece que el reconocimiento y ejecución de la sentencia se hará de acuerdo con la ley del Estado en donde se invoque la sentencia. ${ }^{48}$ El numeral 1으 del artículo IV enlista los documentos que, junto a la demanda, debe presentar la parte que solicita el reconocimiento y la ejecución de la sentencia arbitral. Básicamente es la sentencia arbitral y el acuerdo arbitral, en originales debidamente autenticados o en copia de esos originales. De ahí que se destaque al Convenio de Nueva York por su "sencillez documental" ${ }^{49}$ El numeral 2o del artículo IV indica que si la sentencia arbitral está redactada en idioma extranjero deberá procederse a su traducción competente.

El artículo V enumera, de manera taxativa, las causas que permiten denegar el reconocimiento y ejecución de una sentencia arbitral. Y radica en la parte contra la cual la sentencia arbitral es invocada la carga de probar tales causas. ${ }^{50}$ El artículo VI prevé la posibilidad de aplazar la decisión sobre la ejecución de la sentencia, en caso de que se hubiere solicitado su anulación o suspensión a la autoridad competente del país en donde ella se hubiere dictado. Igualmente, si así lo solicita la parte contra la que se invoca, se podrá ordenar a la otra parte que constituya las garantías que fueren apropiadas. ${ }^{51}$

El artículo VII en su numeral $1^{\underline{0}}$ señala que no se afectan los acuerdos multilaterales o bilaterales que hayan concertado los Estados contratantes

no está circunscrita en su aplicación a las solas materias de derecho mercantil. Por el contrario, su aplicación es general y comprende por ello las materias mercantiles, civiles y administrativas (...)”. Cfr. Grigera Naon, Horacio A., "Reconocimiento y ejecución de laudos arbitrales en América Latina”, en: El arbitraje en los conflictos económicos internacionales, XIII Conferencia Interamericana de Arbitraje Comercial celebrada en Cali en noviembre de 1994, Santafé de Bogotá, Cámara de Comercio de Bogotá, 1995, p. 86

${ }^{46}$ Informe del $36^{\circ}$ período de sesiones del Grupo de Trabajo sobre Arbitraje de la CNUDMI/ UNCITRAL. Naciones Unidas A/CN.9/508. Disponible en Internet: < http://www.uncitral.org>

${ }^{47}$ Ibídem.

${ }^{48}$ Cfr. Monroy Cabra, Arbitraje comercial nacional e internacional, 2 ed. Santafé de Bogotá: Legis, 1998, p. 142.

${ }^{49}$ Cfr. Fernández de la Gándara y Calvo Caravaca, Op. Cit., p. 782.

${ }^{50}$ Cfr. Chillón Medina y Merino Merchán, Op. Cit., p. 501. Cfr. Grigera Naon, Op. Cit., pp. 82-83. Dichas causas se refieren a incapacidad de las partes o invalidez del pacto arbitral, restricciones al derecho de defensa de una de las partes, incongruencia o exceso de la sentencia frente al pacto arbitral, defectos en la constitución del tribunal arbitral y aspectos atinentes a la falta de ejecutoriedad del laudo arbitral.

${ }^{51}$ Cfr. Morales Molina, Op. Cit., p. 28. 
sobre reconocimiento y ejecución de sentencias arbitrales ${ }^{52}$ y contempla la opción de acogerse al derecho más favorable a solicitud de una de las partes interesadas. En el numeral 2 del artículo VII expresamente se dejan sin efecto el Protocolo de Ginebra de 1923 y la Convención de Ginebra de 1927 sobre la ejecución de las sentencias arbitrales extranjeras. ${ }^{53}$

Los artículos VIII, IX y X se refieren a la suscripción, ratificación y adhesión de la Convención. El artículo XI trae una previsión particular de aplicabilidad en los Estados federales o no unitarios. El artículo XII hace relación a la entrada en vigor de la Convención tanto desde el punto de vista internacional como, en particular, para cada Estado ratificante o adherente. Los artículos XIII a XVI traen previsiones respecto de la denuncia de la Convención, del principio de equivalencia en el cumplimiento para cada uno de los Estados contratantes, del deber de notificación del Secretario General de las Naciones Unidas y respecto de los idiomas oficiales de la Convención.

Es ahora, próximos a celebrar medio siglo de vigencia, cuando con mayor pertinencia se puede señalar que la Convención de Nueva York de 1958 se ha constituido en un baluarte en el desenvolvimiento del arbitraje comercial internacional, toda vez que la eficacia y seguridad jurídicas que deben acompañar el final del proceso arbitral se han logrado merced a la señera existencia de dicho tratado internacional y a su impasible y firme aplicación en los diferentes Estados que consintieron en obligarse por él.

\subsection{Convenio sobre arreglo de diferencias relativas a inversiones entre Estados y nacionales de otros Estados, suscrito en Washington el 18 de marzo de 1965}

Por su especial significación para algunos países latinoamericanos receptores de inversión extranjera a través de tratados de protección y promoción de inversiones, cabe reseñar el Convenio sobre arreglo de diferencias relativas a inversiones entre Estados y nacionales de otros Estados, ${ }^{54}$ auspiciado por el Banco

\footnotetext{
${ }^{52}$ Respecto de Colombia se predica el Tratado de derecho procesal internacional de 1889, el Tratado con el Ecuador de 18 de junio de 1903 y la Convención Interamericana sobre Arbitraje Comercial Internacional de Panamá de 1975.

${ }^{53}$ Cfr. Chillón Medina y Merino Merchán, Op. Cit., p. 501. Colombia no adhirió a tales instrumentos.

${ }^{54}$ Ibídem, p. 503. Sostienen los autores ibéricos que “(...) el Tratado de Washington institucionaliza el arbitraje en una materia concreta, la de inversiones extranjeras, integrando, en definitiva, las relaciones entre países industrializados e inversores y aquellos otros poseedores de materias primas, receptores de capital y tecnología (...)”. Cfr. Fernández Masiá, Enrique, Arbitraje en inversiones extranjeras: El procedimiento arbitral en el CIADI. Tirant lo blanch, Valencia, 2004, p. 23.
} 
Mundial ${ }^{55}$ - que es su depositario,$-{ }^{56}$ el cual consta de un preámbulo y 10 capítulos que reúnen 75 artículos.

La estructura de este convenio se resume así: El capítulo I, el cual crea el Centro Internacional de Arreglo de Diferencias relativas a Inversiones (CIADI), ${ }^{57}$ tiene 6 secciones y 24 artículos. El capítulo II (jurisdicción del Centro) comprende los artículos 25 a 27. El capítulo III (conciliación) tiene 3 secciones y finaliza en el artículo 35. El capítulo IV (el arbitraje) tiene 6 secciones y culmina en el artículo $55 .{ }^{58}$ El capítulo $\mathrm{V}$ (sustitución y recusación de conciliadores y árbitros) contiene los artículos 56 a 58. El capítulo VI (costas del procedimiento) regula el tema en 3 artículos y el capítulo VII (lugar del procedimiento) en 2 artículos. El capítulo VIII (diferencias entre Estados contratantes) está compuesto por el artículo 64. El capítulo IX (enmiendas) comprende los artículos 65 y 66. Por último, el capítulo X (disposiciones finales) contiene los artículos 67 a 75.

El Convenio CIADI, que entró en vigor el 14 de octubre de $1966,{ }^{59}$ cuenta a la fecha con 134 países que han depositado sus instrumentos de ratificación. Colombia, a pesar de no haber sido país signatario, adhirió a él, luego de haberse expedido la ley 267 del 29 de enero de 1995 y de haberse obtenido el aval de exequibilidad correspondiente. ${ }^{60}$ Así pues, este significativo instrumento creó y organizó el centro de arbitraje más especializado del mundo en materia de inversiones extranjeras, bajo cuya administración a la fecha se han concluido más de 130 laudos arbitrales, pendiendo algo más de 100 por decidir.

55 Anteriormente, Banco Internacional de Reconstrucción y Desarrollo (BIRD). Cfr. Fernández Masiá, Op. Cit., p. 25, quien señala que “(...) la posibilidad de adoptar un texto convencional (...) fue aprobada mediante la resolución no. 214 en la reunión de Tokio de la Junta de Gobernadores 202 en $1964(\ldots)$ "

${ }^{56}$ Según el artículo 73.

${ }^{57}$ ICSID por sus siglas en inglés. Disponible en Internet: < http://www.worldbank.org/icsid >

${ }^{58}$ Cfr. Bernal Gutiérrez, Op. Cit., pp. 35-37. El distinguido comercialista colombiano y actual director del Centro de Conciliación y Arbitraje de la Cámara de Comercio de Bogotá, comentando las particularidades del convenio, señala que “(...) los procedimientos adoptados tienen como base tres pilares fundamentales que lo desarrollan y permiten la consecución de los objetivos generales del convenio. Son ellos: el carácter eminentemente voluntario, la flexibilidad de los procedimientos y la exclusividad de los mismos (...)". (el resaltado pertenece al texto original).

${ }^{59}$ Ibídem, p. 35. Cfr. Nieto Navia, Rafael. "La paradoja en auge del arbitraje de inversión: iestán los Estados reconsiderando su apoyo al arbitraje? El caso argentino", en: Mantilla-Serrano, Fernando (coord.), Arbitraje internacional. Tensiones actuales, Comité Colombiano de Arbitraje, Legis, Bogotá, 2007, p. 40.

${ }^{60}$ La ley fue declarada exequible por la Corte Constitucional mediante sentencia C-442/96, M. P. Eduardo Cifuentes Muñoz y el convenio fue promulgado por medio del decreto 2738 del 24 de noviembre de 1997. 
Ahora bien, el CIADI, en cuanto instancia arbitral para resolver las disputas surgidas entre los Estados y los inversionistas, supone la existencia de un tratado de protección y promoción de inversiones (conocidos como TPPI), ${ }^{61}$ ya sea bajo la modalidad de tratados multilaterales sobre inversión (TMI) o de tratados bilaterales de inversión (TBIs) ${ }^{62}$ o en los tratados de libre comercio (TLCs), ${ }^{63}$ en los cuales se prevea que la resolución de conflictos se vincula a la denominada "cláusula CIADI", ${ }^{64}$ vale decir, que las controversias sobre inversiones entre particulares y Estados se someten a la jurisdicción de dicho centro de arbitraje así como también cuando, en desarrollo de dichos tratados especializados, en los contratos de inversión que se celebren se incluyan cláusulas compromisorias ${ }^{65}$ que específicamente contemplen que ese arbitraje se surtirá conforme al procedimiento y reglamento del CIADI.

\subsection{Convención interamericana sobre arbitraje comercial internacional, firmada en la Ciudad de Panamá el 30 de enero de 1975}

Merced a los previos trabajos del Comité Jurídico Interamericano y a instancias del desaparecido Consejo Interamericano de Jurisconsultos, la Asamblea General de la Organización de Estados Americanos (OEA), por medio de resolución aprobada el 23 de abril de 1971, convocó a la que habría de ser la Primera Conferencia Especializada Interamericana sobre Derecho Internacional Privado ${ }^{66}$ celebrada en la Ciudad de Panamá entre el 14 y el 30 de enero de 1975.67

De las seis convenciones que se aprobaron el último día de sesiones, se destaca la Convención interamericana sobre arbitraje comercial internacional que, en palabras de los tratadistas Chillón Medina y Merino Merchán, “(...) signi-

${ }^{61}$ Cfr. Fernández Masiá, Op. Cit., p. 34. Cfr. Rigo Sureda, Andrés, "La noción de inversión protegida”, en: Mantilla-Serrano, Fernando (coord.), Arbitraje internacional. Tensiones actuales, Comité Colombiano de Arbitraje, Legis, Bogotá, 2007, pp. 4-5.

${ }^{62}$ También son conocidos como BITs (sigla en inglés de Bilateral Investment Treaties). Cfr. Blackaby, Nigel, "El arbitraje según los tratados de inversión y los capítulos de inversión en los tratados de libre comercio", en: Silva Romero y Mantilla Espinosa (coords.), El Contrato de Arbitraje, Legis, Bogotá, 2005, pp. 287-288. Cfr. Granato, Leonardo. "Protección del inversor extranjero en los tratados bilaterales de inversión". Disponible en Internet: < http://www.eumed.net/libros/2005/ $\lg / \mathrm{lg}$-pie.pdf $>$

${ }^{63}$ Cfr. Rojas Arroyo, Santiago y María Eugenia LLoreda. iTLC? Aspectos jurídicos del Tratado de Libre Comercio entre Colombia y Estados Unidos, Norma, Bogotá, 2007, pp. 294 y ss.

${ }^{64}$ Fernández Masiá, Op. Cit., p. 87.

${ }^{65}$ Cfr. Blackaby, Op. Cit., p. 287.

${ }^{66}$ Estas conferencias se conocen por la sigla CIDIP, acompañadas del número romano correspondiente.

${ }^{67}$ Cfr. Monroy Cabra, Marco Gerardo, Conferencias interamericanas de Panamá (1975) y Montevideo 
ficó ciertamente un paso decisivo en la regulación del arbitraje internacional en los países americanos (...)" ${ }^{68}$ La Convención de Panamá fue firmada por doce Estados el 30 de enero de 1975 y, de acuerdo con su artículo 10º entró en vigor el trigésimo día a partir de la fecha de depósito del segundo instrumento de ratificación, es decir, el 16 de junio de $1976 .{ }^{69}$ Colombia la aprobó, tardíamente, por medio de la Ley 44 de 1986 y la ratificó el 18 de noviembre de $1986 .{ }^{70}$

La Convención de Panamá de 1975 consta de trece artículos ${ }^{71}$ y, no obstante algunas diferencias, como las referentes al ámbito material de aplicación del arbitraje y la exigencia de determinados requisitos de forma, puede afirmarse que guarda marcada similitud con la Convención de Nueva York de $1958 .{ }^{72}$

El artículo $1^{\mathrm{O}}$ se refiere al acuerdo arbitral, sin distinguir entre cláusula compromisoria y compromiso y lo circunscribe a los negocios de carácter mercantil. ${ }^{73}$ De la misma manera, exige que dicho acuerdo conste por escrito. El artículo 2으 hace relación al nombramiento de los árbitros, quienes lo serán por la propia voluntad de las partes. Sin embargo, se prevé la delegación de tal designación a un tercero, persona natural o jurídica. Finalmente, la norma contempla la posibilidad de designar árbitros extranjeros. ${ }^{74} \mathrm{El}$ artículo $3^{\mathrm{o}}$ establece como regla principal que las partes determinen expresamente el procedimiento arbitral. Si guardaren silencio sobre el particular, la norma, con carácter supletivo, señala que se aplicarán las reglas de procedimiento

(1979) sobre derecho internacional privado, Ediciones Rosaristas, Bogotá, 1979, p. 6.

${ }^{68}$ Cfr. Chillón Medina y Merino Merchán, Op. Cit., p. 507.

${ }^{69}$ Ibídem, p. 507. Cfr. Monroy Cabra, Arbitraje comercial nacional e internacional, 2 ed. Santafé de Bogotá, Legis, 1998., p. 153.

${ }^{70}$ Cfr. Monroy Cabra, Op. Cit. en pie de página anterior, p. 154.

$204 \quad{ }^{71}$ Cfr. Benetti Salgar, Julio, "La Convención de Panamá sobre Arbitraje Comercial Internacional", en: Alternativas a la Justicia Institucional. Arbitraje. Conciliación. Conferencias, Biblioteca de la Cámara de Comercio de Bogotá, Bogotá, 1986, p. 139. El texto de la Convención de Panamá de 1975 se encuentra disponible en Internet: < http://www.oas.org/juridico/spanish/tratados/b-35. html>

${ }^{72}$ Cfr. Benetti Salgar, Op. Cit., p. 139. Cfr. Chillón Medina y Merino Merchán, Op. Cit.,p. 507. Supra. 4.8 .

${ }^{73}$ Cfr. Benetti Salgar, Op. Cit., p. 143. Cfr. Grigera Naon, Op. Cit., p. 86.

${ }^{74}$ Respecto del arbitraje comercial internacional en Colombia, la Convención de Panamá de 1975 regulará lo atinente al nombramiento de los árbitros, de acuerdo con la remisión que hace el artículo 2 de la Ley 315 del 12 de septiembre de 1996. Cfr. Martínez Neira, Néstor Humberto, "Arbitraje Comercial Internacional", en: El arbitraje en los conflictos económicos internacionales, XIII Conferencia Interamericana de Arbitraje Comercial celebrada en Cali en noviembre de 1994, Santafé de Bogotá, Cámara de Comercio de Bogotá, 1995, p. 132, quien puntualiza diciendo que “(...) la nominación de árbitros extranjeros en arbitrajes comerciales internacionales (...) obedece a la consideración de que el árbitro internacional no tiene foro (...) Este criterio significa que 
de la Comisión Interamericana de Arbitraje Comercial (CIAC) ${ }^{75}$ El artículo 4 o hace relación a la fuerza ejecutiva de las sentencias, siempre y cuando su reconocimiento y ejecución se ajuste a las leyes procesales del país donde se vaya a ejecutar y lo que al respecto dispongan los tratados internacionales. El artículo 5o de la Convención de Panamá es, prácticamente, una reproducción literal del artículo V de la Convención de Nueva York de $1958,{ }^{76}$ en cuanto a la enumeración taxativa de las causas ${ }^{77}$ por las cuales el reconocimiento y ejecución de una sentencia arbitral se puede denegar. Igual acontece con el artículo $6^{\circ}$ respecto de la posibilidad de aplazar la decisión sobre la ejecución de la sentencia. El artículo $7^{\underline{0}}$ señala que la convención estará abierta a los Estados miembros de la OEA. El artículo $8^{\circ}$ versa sobre las ratificaciones y el artículo 9으 sobre las adhesiones. El artículo $10^{\circ}$ indica la forma como entra en vigor. El artículo $11^{\mathrm{O}}$ se refiere a la aplicación en Estados plurilegislativos. El artículo $12^{\circ}$ se refiere a la denuncia de la convención y el artículo $13^{\circ}$ al depósito de la convención.

3.11. Convención interamericana sobre eficacia extraterritorial de las sentencias y laudos arbitrales extranjeros, firmada en Montevideo el 8 de mayo de 1979

Esta convención fue aprobada dentro del marco de la Segunda Conferencia Especializada Interamericana sobre Derecho Internacional Privado (CIDIP II), celebrada en la ciudad de Montevideo del 23 de abril al 8 de mayo de $1979 .{ }^{78}$ De las siete convenciones y el protocolo adicional que se aprobaron, la Convención interamericana sobre eficacia extraterritorial de las sentencias y laudos arbitrales extranjeros tiene su origen en el proyecto previamente elaborado por el Comité Jurídico Interamericano en 1977.

La Convención de Montevideo sobre eficacia de laudos extranjeros fue firmada por 14 Estados el 8 de mayo de 1979 y, de acuerdo con su artículo

la calidad de árbitro internacional no deviene de un aparato judicial perteneciente a un Estado particular (...)".

${ }^{75}$ Supra. 2.7. Cfr. Benetti Salgar, Op. Cit., p. 141.

${ }^{76}$ Cfr. Monroy Cabra, Marco Gerardo, Conferencias Interamericanas de Panamá (1975) y Montevideo (1979) sobre Derecho Internacional Privado. Bogotá: Ediciones Rosaristas, 1979, p. 35. Cfr. Benetti Salgar, Op Cit., p. 143. Supra. 4.6.

77 Tales causas hacen referencia a la incapacidad de las partes o a la invalidez del acuerdo de arbitraje, a las restricciones al derecho de defensa de una de las partes, incongruencia o exceso de la sentencia frente al pacto arbitral, deficiencias en la constitución del tribunal arbitral y aspectos relativos a la no ejecutoria del laudo arbitral.

${ }^{78}$ Cfr. Monroy Cabra, Marco G., Op. Cit. en pie de página 76, p. 74. El texto de la Convención de Montevideo de 1979 se encuentra disponible en Internet: < http://www.oas.org/juridico/spanish/ tratados/b-41.html> 
11ํㅡ, entró en vigor el trigésimo día a partir de la fecha de depósito del segundo instrumento de ratificación, es decir, el 14 de junio de $1980 .{ }^{79}$ Colombia la aprobó por medio de la Ley 16 de 22 de enero de 1981 y la ratificó, sin reservas, el 9 de octubre de 1981.80

La Convención de Montevideo de 1979 consta de 14 artículos y se debe entender como complementaria ${ }^{81}$ de la Convención de Panamá de 1975. El artículo $1^{\circ}$ establece el ámbito de aplicación de la Convención de Montevideo, especificando que comprenderá las sentencias judiciales y los laudos arbitrales dictados en procesos civiles, comerciales o laborales, a menos que en el momento de la ratificación el Estado parte hiciera una reserva en cuanto a limitar su aplicabilidad a las sentencias de condena en materia patrimonial. Asimismo, el Estado parte podrá declarar en ese momento que la convención también se aplique a resoluciones que terminen el proceso, a resoluciones dictadas por autoridades que ejerzan funciones jurisdiccionales y a sentencias penales.

El artículo $2^{\mathrm{O}}$ enlista los requisitos para la eficacia extraterritorial de las sentencias y laudos arbitrales extranjeros, presentando así cierta afinidad con el artículo 694 del Código de procedimiento civil colombiano, relativo a los requisitos para que la sentencia o laudo extranjero surta efectos en el país. El artículo 3ํㅗ señala cuáles son los documentos de comprobación indispensables para solicitar el cumplimiento de las sentencias, laudos y resoluciones jurisdiccionales, guardando alguna similitud con lo dispuesto por el artículo IV de la Convención de Nueva York de $1958 .{ }^{82}$ El artículo 4o contempla la posibilidad de exequátur parcial, previa petición de la parte interesada. El artículo 5으 mantiene en el Estado de su presentación el beneficio de pobreza reconocido en el estado de origen de la sentencia. El artículo $6^{0}$ plantea un criterio uniforme de aplicación, en la medida en que expresa que los procedimientos para asegurar la eficacia de las sentencias y laudos arbitrales, e incluso la propia competencia de los respectivos órganos judiciales, sean regulados por la ley del Estado en que se solicita su cumplimiento. El artículo $7^{\circ}$ señala que la convención estará abierta a los Estados miembros de la OEA. El artículo 8o versa sobre las ratificaciones y el artículo 9ํㅜㄹ sobre las adhesiones. El artículo 10 prevé la posibilidad de formular reservas, el artículo $11^{\circ}$ indica la forma como entra en vigor. El artículo $12^{\circ}$ se refiere a la aplicación en Estados plurilegislativos. El artículo $13^{\circ}$ se refiere a la denuncia de la convención y el artículo $14^{\circ}$ al depósito de la convención.

\footnotetext{
${ }^{79}$ Cfr. Chillón Medina y Merino Merchán, Op. Cit., p. 508. Cfr. Monroy Cabra, Arbitraje comercial nacional e internacional, 2 ed. Santafé de Bogotá, Legis, 1998, p. 159.

${ }^{80}$ Cfr. Monroy Cabra, Op. Cit. en pie de página 79, p. 159.

${ }^{81}$ Cfr. Chillón Medina y Merino Merchán, Op. Cit., p. 508.

${ }^{82}$ Cfr. Benetti Salgar, Op. Cit., p. 142.
} 
Esta convención, en efecto, completa e integra la Convención de Panamá de 1975 sobre arbitraje comercial internacional, logrando así un conjunto regulador sobre el tema para los países latinoamericanos que mediante ratificación o adhesión hayan manifestado su consentimiento a obligarse por dicho compendio de tratados.

\section{Conclusión}

El anterior periplo ilustrativo alrededor de diversos instrumentos internacionales relacionados con el arbitraje comercial internacional en América Latina demuestra fehacientemente que desde hace mucho tiempo este tema ya se había ambientado en nuestra latitud, inclusive con alguna anticipación a la regulación europea, y que se habían previsto mecanismos para su eficacia en los correspondientes territorios de los países ratificantes o adherentes a tan variado conjunto normativo convencional.

Surge, entonces, una lógica inquietud relacionada con la validez material de algunos de estos tratados, así como con la eficacia de su aplicación, en la medida en que por el hecho de presentar homogeneidad regulatoria plantean un problema de vigencia que, en realidad, para una mayor claridad de los operadores jurídicos, debería hoy canalizarse a través de la Organización de los Estados Americanos, en cuanto foro jurídico por excelencia sobre los temas de derecho internacional privado del continente americano, ya a través de la expedición de un texto refundido que organice los contenidos y centralice la eficaz aplicación de la normatividad, o ya mediante una declaración que señale, indefectiblemente, que es el conjunto de las convenciones de Panamá (1975) y Montevideo (1979) el acervo instrumental que con más idoneidad regula tal temática.

La aspiración pretendida al haber emprendido este ensayo se circunscribía a reseñar tanto la travesía histórica del arbitraje comercial internacional en el territorio latinoamericano, como la regulación contenida en varias de las convenciones internacionales concebidas en tal entorno, con el propósito de ilustrar esquemáticamente a una audiencia in crescendo conformada por estudiantes, árbitros en ciernes y estudiosos del arbitraje, con la esperanza de que este sea un esfuerzo académico que genere inquietudes en futuros trabajos de derecho comparado.

\section{Bibliografía}

Alvarez Londoño S.J., Luis Fernando y Diego Ricardo Galán Barrera, Derecho Internacional Privado (Parte General). Pontificia Universidad Javeriana. 
Facultad de Ciencias Jurídicas. Estudios de Derecho Internacional 4 (CEDI). 1aㅡ reimpresión. Bogotá, Javegraf, 2002.

Benetti Salgar, Julio, El arbitraje en el derecho colombiano. Temis, Santafé de Bogotá, 1994.

Benetti Salgar, Julio. "La Convención de Panamá sobre arbitraje comercial internacional", en: Alternativas a la Justicia Institucional. Arbitraje. Conciliación. Conferencias, Biblioteca de la Cámara de Comercio de Bogotá, Bogotá, 1986.

Botero Sanclemente, Ana María y Nestor Raúl Correa Henao, Arbitramento Internacional, Bogotá, Cámara de Comercio de Bogotá, 2002.

Blackaby, Nigel, "El arbitraje según los tratados de inversión y los capítulos de inversión en los tratados de libre comercio", en: Silva Romero y Mantilla Espinosa (coords.), El contrato de arbitraje, Facultad de Jurisprudencia de la Universidad del Rosario. Bogotá, Legis, 2005.

Bueno Guzmán, Carlos, "Ley modelo de la CNUDMI sobre arbitraje comercial internacional. Viena, 1985”, en: Universitas № 101, Pontificia Universidad Javeriana, Facultad de Ciencias Jurídicas, junio 2001, Bogotá, Javegraf.

Calvo Caravaca, Alfonso-Luis y Javier Carrascosa González, Derecho Internacional Privado, Vol 1.6 ed. Granada, Comares, 2005.

Chillón Medina, José María y José Fernando Merino Merchán, Tratado de arbitraje privado interno e internacional. 2 ed. Madrid, Civitas, 1991.

Crespo Ríos, Lyda Mercedes, Práctica del arbitraje internacional en Colombia. Tesis de Grado. Universidad de San Buenaventura de Cali. Santiago de Cali, 2003.

Dotación Carnegie para la Paz Internacional, Conferencias Internacionales Americanas. 1889-1936, Publicaciones de la Dotación Carnegie para la Paz Internacional, Washington, 1938.

Eyzaguirre Echeverria, Rafael, "Ventajas del arbitraje. Eficacia y validez en el derecho iberoamericano", en: Alternativas a la Justicia Institucional. Arbitraje. Conciliación. Conferencias. Biblioteca de la Cámara de Comercio de Bogotá, Bogotá, 1986.

Fernández de la Gándara y Alfonso-Luis Calvo Caravaca, El arbitraje mercantil internacional, Madrid, Tecnos, 1989.

Fernández de la Gándara, Luis y Alfonso-Luis Calvo Caravaca, Derecho mercantil internacional. 2 ed. Madrid, Tecnos, 1995.

Fernández Masiá, Enrique. Arbitraje en inversiones extranjeras: El procedimiento arbitral en el CIADI, Valencia: Tirant lo blanch, 2004.

Garro, Alejandro, "Armonización y Unificación del derecho privado en América Latina: esfuerzos, tendencias y realidades", Saggi, Conference e Seminari 5. Centro di studi e ricerche di diritto comparato e straniero (directo da M. J. Bonell).

\section{PRECEDENTE}


Gamboa Morales, Nicolás, "La inmunidad soberana de jurisdicción en el marco del arbitraje comercial internacional. Evolución y actualidad". Disponible en Internet:

$<$ http://acj.org.co/index.phpcont=actividad_academica/posesion_gamboa_morales.htm $>$

Ḡonzález de Cancino, Emilssen, “Arbitraje Romano", en: Silva Romero y Mantilla Espinosa (coords.), El contrato de arbitraje, Facultad de Jurisprudencia de la Universidad del Rosario, Bogotá, Legis, 2005.

Granato, Leonardo. "Protección del inversor extranjero en los tratados bilaterales de inversión”. Disponible en Internet: < http://www.eumed.net/ libros/2005/lg/lg-pie.pdf>

Grigera Naon, Horacio A., "Reconocimiento y ejecución de laudos arbitrales en América Latina", en: El Arbitraje en los Conflictos Económicos Internacionales, XIII Conferencia Interamericana de Arbitraje Comercial, celebrada en Cali en noviembre de 1994. Santafé de Bogotá, Cámara de Comercio de Bogotá, 1995.

Jaramillo Jaramillo, Carlos Ignacio, Solución alternativa de conflictos en el seguro y en el reaseguro, Pontificia Universidad Javeriana. Facultad de Ciencias Jurídicas. Asociación Internacional de Derecho de Seguros, Comité IberoLatinoamericano de AIDA-CILA, Colección Internacional № 1, Santafé de Bogotá, 1998.

Mac Lean U., Roberto. Derecho del comercio internacional (Nuevas tendencias), Bogotá: Temis, 1982.

Martínez Neira, Néstor Humberto, "Arbitraje Comercial Internacional", en: El Arbitraje en los Conflictos Económicos Internacionales, XIII Conferencia Interamericana de Arbitraje Comercial, celebrada en Cali en noviembre de 1994. Santafé de Bogotá: Cámara de Comercio de Bogotá, 1995.

Monroy Cabra, Marco Gerardo. Conferencias Interamericanas de Panamá (1975) y Montevideo (1979) sobre Derecho Internacional Privado. Bogotá: Ediciones Rosaristas, 1979.

Monroy Cabra, Marco Gerardo, "Consideraciones sobre el arbitraje comercial en Colombia", en: Alternativas a la Justicia Institucional. Arbitraje. Conciliación, Conferencias. Biblioteca de la Cámara de Comercio de Bogotá, Bogotá, 1986.

Monroy Cabra, Marco Gerardo. "Comentarios al texto de una ley modelo sobre arbitraje comercial internacional de Uncitral. Aprobado por el grupo de trabajo sobre prácticas comerciales internacionales en nov. 24/84". en: Alternativas a la Justicia Institucional. Arbitraje. Conciliación, Conferencias. Biblioteca de la Cámara de Comercio de Bogotá, -Bogotá, 1986.

Monroy Cabra, Marco Gerardo. Tratado de derecho internacional privado. 5 ed. Santa Fe de Bogotá, Temis, 1998. 
Monroy Cabra, Marco Gerardo. Arbitraje comercial nacional e internacional, 2 ed. Santafé de Bogotá, Legis, 1998.

Montoya, Ulises, "La Comisión Interamericana de Arbitraje Comercial", en: Revista Iberoamericana de Arbitraje y Mediación.

Morales Molina, Hernando. "El arbitraje nacional e internacional en Colombia”, en: Alternativas a la Justicia Institucional. Arbitraje. Conciliación, Conferencias, Biblioteca de la Cámara de Comercio de Bogotá, Bogotá, 1986.

Nieto Navia, Rafael, "La paradoja en auge del arbitraje de inversión: ¿están los Estados reconsiderando su apoyo al arbitraje? El caso argentino”, en: Mantilla-Serrano, Fernando (coord.), Arbitraje Internacional. Tensiones actuales, Comité Colombiano de Arbitraje, Bogotá, Legis, 2007.

Pérez García, Arturo Rafael, "Una nueva forma de valorar el tratado de libre comercio de América del Norte, a partir de las controversias suscitadas de acuerdo con el capítulo once", en: Revista del Centro de Investigación Universidad La Salle (ene-jun), V. 5. № 20. México, 2003, p. 107-111.

Rigo Sureda, Andrés, "La noción de inversión protegida", en: MantillaSerrano, Fernando (coord), Arbitraje Internacional. Tensiones actuales, Comité Colombiano de Arbitraje, Bogotá, Legis, 2007.

Rojas Arroyo, Santiago y María Eugenia Lloreda P., iTLC? Aspectos jurídicos del Tratado de Libre Comercio entre Colombia y Estados Unidos, Bogotá, Norma, 2007.

Secretaría General de la Organización de los Estados Americano, Textos de los Tratados de Montevideo sobre Derecho Internacional Privado, Comité Jurídico Interamericano, Washington, marzo de 1973.

Uribe Vargas, Diego. Solución pacífica de conflictos internacionales. La paz es una tregua, Bogotá, Centro Editorial de la Universidad Nacional de Colombia, 1987. 